\author{
Marquette University \\ e-Publications@Marquette
}

2001

\title{
An XPS Investigation of Thermal degradation and Charring of Cross-linked Polyisoprene and Polychloroprene
}

Jlanwei Hao

Beijing Institute of Technology

Charles A. Wilkie

Marquette University, charles.wilkie@marquette.edu

Jiangqi Wang

Beijing Institute of Technology

Follow this and additional works at: https://epublications.marquette.edu/chem_fac

Part of the Chemistry Commons

\section{Recommended Citation}

Hao, Jlanwei; Wilkie, Charles A.; and Wang, Jiangqi, "An XPS Investigation of Thermal degradation and Charring of Cross-linked Polyisoprene and Polychloroprene" (2001). Chemistry Faculty Research and Publications. 159.

https://epublications.marquette.edu/chem_fac/159 
Marquette University

e-Publications@Marquette

\section{Chemistry Faculty Research and Publications/College of Arts and Sciences}

This paper is NOT THE PUBLISHED VERSION; but the author's final, peer-reviewed manuscript. The published version may be accessed by following the link in th citation below.

Polymer Degradation and Stability, Vol. 71, No. 2 (2001): 305-315. DOI. This article is (C Elsevier and permission has been granted for this version to appear in e-Publications@Marquette. Elsevier does not grant permission for this article to be further copied/distributed or hosted elsewhere without the express permission from Elsevier.

\section{An XPS investigation of thermal degradation and charring of cross-linked polyisoprene and polychloroprene}

\section{Jianwei Hao}

National Laboratory of Flame Retardant Materials, School of Chemical Engineering and Materials Science, Beijing Institute of Technology, Beijing, People's Republic of China

Charles A. Wilkie

Department of Chemistry, Marquette University, Milwaukee, WI

Jianqi Wang

National Laboratory of Flame Retardant Materials, School of Chemical Engineering and Materials Science, Beijing Institute of Technology, Beijing, People's Republic of China

\footnotetext{
Abstract

Our interest in butadiene-containing polymers had led to an investigation of the thermal degradation of polyisoprene, PIP, and polychloroprene, PCP. The connection between cross-linking and thermal stability through an examination of PIP and PCP has been reported. Like the course of thermogravimetric analysis (TGA) the cross-linking and charring of polymers subjected to heat can also be experimentally observed as function of temperatures by the pseudo-in-situ XPS (X-ray Photoelectron Spectroscopy). Data acquisition of C1s spectra as
} 
function of temperature permits us to explore: (1) the extent of cross-linking and/or carbon accumulation of systems of PCP and PIP with/without initiators, BPO and DCP, via the analysis of the relative intensity versus temperature; and (2) the onset of charring by determining the limiting transition temperature ( $\mathrm{LT}_{\mathrm{GRL}}$ ) of the graphite-like structure and particularly the plasmon loss $\left(\Delta E_{\mathrm{L}}\right)$.

\section{Keywords}

\section{XPS, Thermal degradation, Cross-linking, Charring, PIP, PCP}

\section{Introduction}

There has been previous work from these laboratories on the relationship between cross-linking and carbon accumulation (charring) of non-cross-linked and cross-linked polymers. This has included work on polyamide$6^{[1]}$ and butadiene-containing polymers ${ }^{[2]}$. Quite recently work has appeared on polyisoprene (PIP) and polychloroprene (PCP) both of which undergo cross-linking by a thermal process as well as an initiator-enhanced thermal cross-linking ${ }^{[3]}$. There are a number of issues concerning the measure of both processes that must be addressed and X-ray photoelectron spectroscopy, XPS, provides a very useful technique to address these questions. In addition to answering these questions, an intent of this work is to show the value of an XPS investigation in better understanding the process of char formation.

\section{Experimental}

For XPS experiments a thin film, with a thickness in the order of microns, must be prepared. Dilute polymeric solutions were obtained by the dissolution of polymer in chloroform, followed by pouring these solutions onto aluminum foil, which had been treated with sulfuric acid, then thoroughly washing with distilled water, followed by organic solvents. The required thin films were obtained by permitting the solvent to evaporate.

The preparation of the samples for initiator-enhanced thermal cross-linking was accomplished by dissolving the polymer, together with $2 \mathrm{mmol}$ benzoyl peroxide (BPO) or dicumyl peroxide (DCP) in $25 \mathrm{ml}$ chloroform in a $100 \mathrm{ml}$ round bottom flask. The resulting solution was then treated as above for the preparation of the virgin polymer samples. The solvent was allowed to evaporate at room temperature for $24 \mathrm{~h}$. Each thin film of the polymer and initiator combination was sealed under vacuum in an ampoule. The samples were then placed in an oil bath at $70^{\circ} \mathrm{C}$ (for BPO-containing samples) or $120^{\circ} \mathrm{C}$ (for DCP-containing samples) for 3-24 h. At the conclusion of the reaction, the ampoules were opened and the samples were removed and analyzed.

\section{Results and discussion}

\subsection{Thermal degradation and charring of un-crosslinked PCP and PIP}

In previous work $[4],[5],[6],[7],[8]$, it has been shown that the cross-linking and charring of polymers subjected to heat can be experimentally observed as a function of temperature by the pseudo-in-situ XPS (X-ray photoelectron spectroscopy). This is similar to the experiment that can be performed by thermogravimetry (TGA), but is more sensitive.

\subsubsection{PCP}

The data for PCP is shown in Table 1, Table 2 and Fig. 1, Fig. 2, Fig. 3. The important parameters derived from this work to characterize cross-linking and char formation included the relative intensity of carbon, the plasmon loss peak $\left(\Delta E_{\mathrm{L}}\right)$ in the C1s spectra and the atomic concentration of chlorine in the C12p spectra. All parameters, as shown in Table 1 from left to right, can be defined as follows: C1s (the 2nd column) is the binding energy of the main peak in C1s spectra; CPS and intensity \% (the 3rd column) represents the counts per second of C1s photoelectrons and the relative intensity referencing to the CPS at room temperature, plasmon loss peak $\left(\Delta E_{\mathrm{L}}\right)$ 
(the fifth column) in C1s spectrum is the difference between values in the 4th and 2nd columns; and shake-up (satellite) peak (the last column) denotes $\pi-\pi^{*}$ transition originating from benzene moieties.

Table 1. XPS data for C1s of PCP thin film on Al foil

\begin{tabular}{|c|c|c|c|c|c|c|}
\hline Temperature & C1s & C1s & & C1s & C1s & C1s \\
\hline$\left({ }^{\circ} \mathrm{C}\right)$ & $(\mathrm{eV})$ & CPS & Intensity (\%) & Plasmon (eV) & $\Delta E_{\mathrm{L}}(\mathrm{eV})$ & shake-up $(e V)$ \\
\hline 25 & 285.9 & 48800 & 0.0 & 308.8 & 22.9 & 292.9 \\
\hline 100 & 285.9 & 49020 & 0.5 & 308.7 & 22.8 & 292.7 \\
\hline 150 & 286.3 & 49160 & 0.7 & 308.9 & 22.6 & 292.9 \\
\hline 200 & 286.3 & 49460 & 1.4 & 309.0 & 22.7 & 292.9 \\
\hline 250 & 286.2 & 50120 & 2.7 & 309.0 & 22.8 & 292.7 \\
\hline 280 & 286.0 & 52550 & 7.7 & 309.2 & 23.2 & n.d. $\stackrel{a}{a}$ \\
\hline 310 & 285.7 & 54210 & 11.1 & 309.2 & 23.5 & n.d. \\
\hline 330 & 285.6 & 55580 & 13.9 & 309.3 & 23.7 & n.d. \\
\hline 350 & 285.3 & 56200 & 15.2 & 309.3 & 24.0 & n.d. \\
\hline 360 & 285.1 & 57710 & 18.3 & 309.2 & 24.1 & n.d. \\
\hline 370 & 284.9 & 59310 & 21.5 & 311.2 & 26.3 & n.d. \\
\hline 380 & 284.9 & 59520 & 22.0 & 311.3 & 26.4 & n.d. \\
\hline 400 & 284.9 & 59640 & 22.2 & 311.2 & 26.3 & n.d. \\
\hline 420 & 284.9 & 59720 & 22.4 & 311.2 & 26.3 & n.d. \\
\hline 450 & 284.9 & 56690 & 16.2 & 311.4 & 26.5 & n.d. \\
\hline 500 & 284.9 & 56630 & 16.1 & 311.5 & 26.6 & n.d. \\
\hline
\end{tabular}

a n.d.: not detectable.

Table 2. XPS data for C12p and C1s of PCP thin film on Al foil

\begin{tabular}{|c|c|c|c|}
\hline Temperature $\left({ }^{\circ} \mathrm{C}\right)$ & C12p & & C1s \\
\hline & CPS & r.i. (\%) & $c[\mathbb{c} / c \square \mid \mathrm{b}$ \\
\hline 25 & 20068 & 100 & $3 / 1$ \\
\hline 100 & 19862 & 98.97 & - \\
\hline 150 & 79331 & 96.33 & - \\
\hline 200 & 17852 & 88.96 & $3.5 / 1$ \\
\hline 250 & 12555 & 62.56 & - \\
\hline 280 & 8062 & 40.17 & $9 / 1$ \\
\hline 310 & 3741 & 18.64 & - \\
\hline 330 & 1352 & 6.74 & $58 / 1$ \\
\hline 350 & 254 & 1.27 & - \\
\hline 360 & 212 & 1.06 & - \\
\hline 370 & 104 & 0.52 & 99.9/1 \\
\hline 380 & n.d. & n.d. & - \\
\hline 400 & n.d. & n.d. & - \\
\hline 420 & n.d. & n.d. & - \\
\hline 450 & n.d. & n.d. & - \\
\hline 500 & n.d. & n.d. & - \\
\hline
\end{tabular}

aPercentage of chlorine remained in the solids.

$\mathrm{bc} \square / \mathrm{c} \square \mathrm{d}$ represents the ratio of carbon atoms linked to carbon over that of carbons linked to chlorine. 


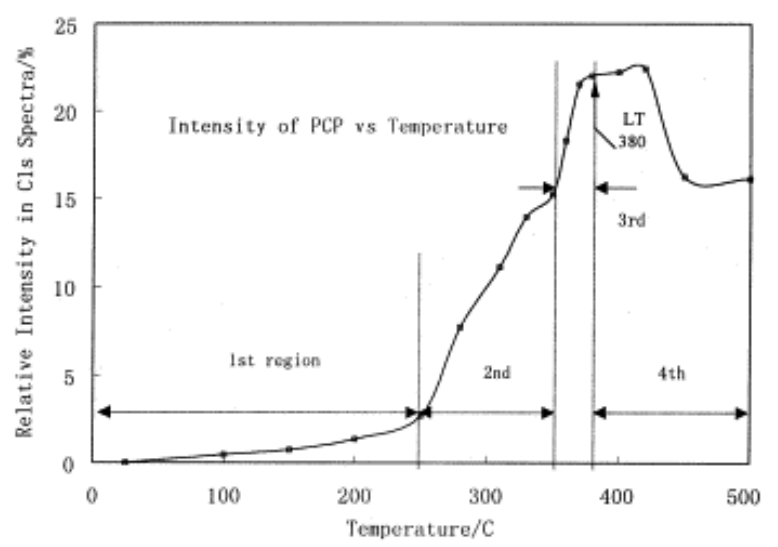

Fig. 1. Relative intensity (\%) of PCP vs temperature.

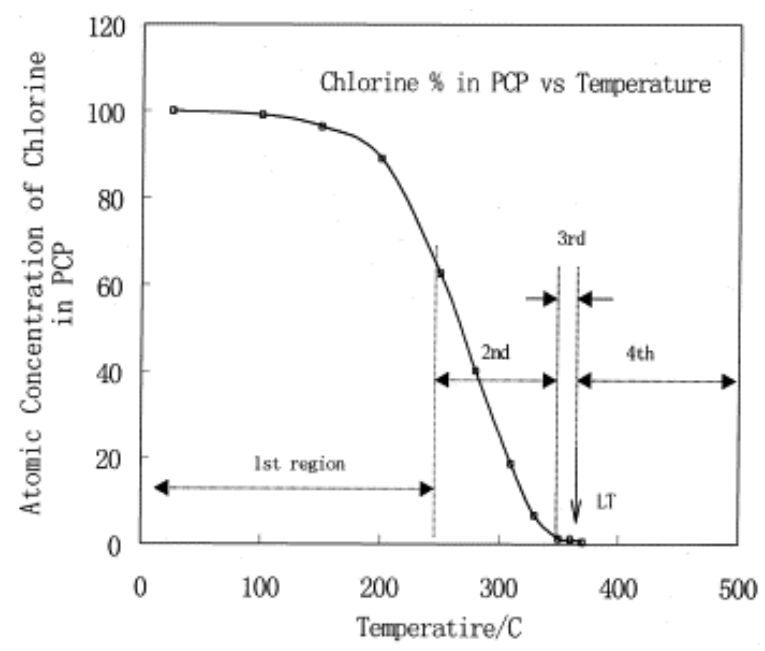

Fig. 2. Atomic concentration of chlorine in PCP as a function of temperature.

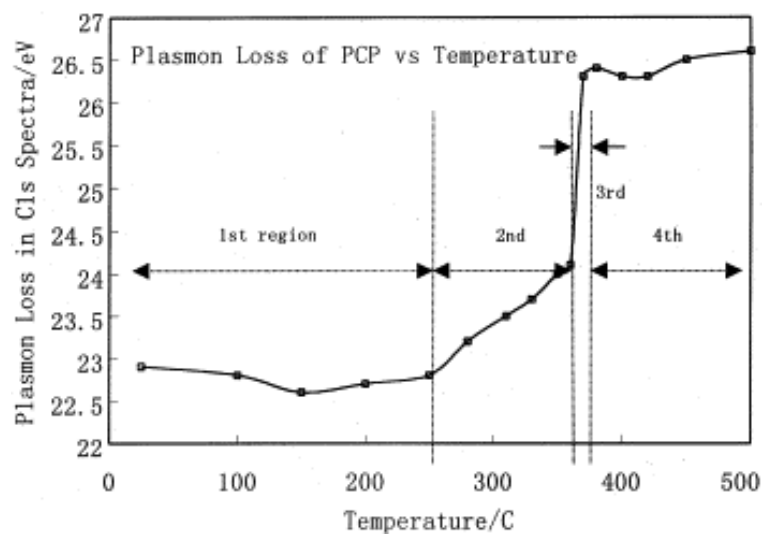

Fig. 3. Plasmon loss $\left(\Delta E_{\mathrm{L}}\right)$ in $\mathrm{C} 1 \mathrm{~s}$ spectra of $\mathrm{PCP}$ vs temperature.

In Fig. 1, four distinctly different temperaure regions can be described: 1 st region (ambient $-250^{\circ} \mathrm{C}$ ), 2nd region $\left(250-350^{\circ} \mathrm{C}\right), 3 \mathrm{rd}$ region $\left(350-380^{\circ} \mathrm{C}\right)$ and 4 th region $\left(>380^{\circ} \mathrm{C}\right)$. The absence of a negative peak in the first region indicates the absence of adventitious contamination of this sample, very often met in modern surface analytical techniques, such as XPS, AES (Auger electron spectroscopy), ISS (ion scattering spectroscopy), and SIMS (secondary ion mass spectroscopy), etc. Such contamination is usually observed and its absence must be

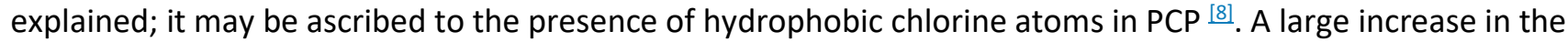


relative intensity within the 2 nd region, which continues but, with a change in slope, during the 3 rd region, is in fairly good agreement with the available information on gel content and swelling ratio ${ }^{[3]}$, and this shows that the extent of cross-linking and the cross-link density increases as the temperature increases. Above $420^{\circ} \mathrm{C}$ the relative intensity begins to decrease, perhaps due to pyrolysis and/or evaporation of the char.

The concentration of chlorine atoms in PCP decreases as the temperature increases and falls to zero at $380^{\circ} \mathrm{C}$, which lies at the border between the 3rd and 4th region (Fig. 2). The thermal degradation of PCP takes place in two stages, i.e. elimination of hydrogen chloride, followed by degradation of the backbone ${ }^{[9]}$. The evolution of $\mathrm{HCl}$ is observed at as early as $100^{\circ} \mathrm{C}$, because of the much higher sensitivity of the XPS technique in the surface layers compared to TGA in the bulk. The ratio of $C \square / C \square \mathrm{I}$, as indicated in Table 2, is the relative amount of carbon attached to another carbon relative to that attached to chlorine; this increases with temperature, indicating the loss of $\mathrm{HCl}$, and finally reaches the value of this ratio, $99.9 / 1$ at $370^{\circ} \mathrm{C}$. Table 3 provides a comparison between XPS and the conventional techniques $\stackrel{[10]}{\text {. }}$

Table 3. Comparison of the temperature $T_{x}$ at fixed chlorine loss $\%$ in PCP by different techniques

\begin{tabular}{|l|c|c|}
\hline \multicolumn{1}{|c|}{$\boldsymbol{T}_{\mathbf{x}}$ and technique } & $\boldsymbol{T}_{\mathbf{x}}\left({ }^{\circ} \mathbf{C}\right)$ & \\
\hline \multicolumn{1}{|c|}{ Chlorine loss (\%) } & XPS & Isothermal thermolysis [8] \\
\hline On-set $\left(T_{1.0}\right)$ & 100 & $150-200$ \\
\hline $77\left(T_{77}\right)$ & 300 & 380 \\
\hline At the end (ca. 90\% loss) & 380 & 420 \\
\hline
\end{tabular}

The Limiting Transition Temperature of Graphite-like Structure, $\mathrm{LT}_{\mathrm{GRL}}$ is used to characterize the charring of

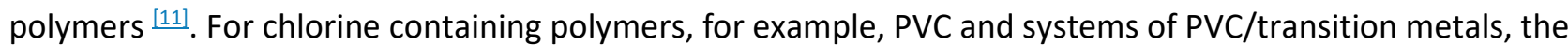
$\mathrm{LT}_{\mathrm{GRL}}$ were taken as the temperatures at which the chlorine atoms just completely vanish, corresponding to the maxima in the plots of relative intensity in C1s spectra vs temperature [12], [13], [14], [15]; in other words, charring defined by $L_{\text {GRL }}$ Occurs just subsequent to the complete loss of chlorine atoms. In Fig. 1 the LT GRL of PCP was determined to be $380^{\circ} \mathrm{C}$ as indicated by the arrow, which was caught up with the deep increase in $\Delta E_{\mathrm{L}}$ within the narrow region (Fig. 3).

Here, the plasmon loss $\left(\Delta E_{\mathrm{L}}\right)$ in C1s spectra can also be divided into four regions, similar to that observed for the C1s spectra, i.e. 1 st region (ambient $\left.-250^{\circ} \mathrm{C}\right)$, 2nd $\left(250-360^{\circ} \mathrm{C}\right), 3 \mathrm{rd}\left(360-380^{\circ} \mathrm{C}\right)$ and 4 th $\left(>380^{\circ} \mathrm{C}\right)$. Following the 2 nd region of moderate cross-linking, a dramatic increase in $\Delta E_{\mathrm{L}}$ from 24.1 to $26.4 \mathrm{eV}$ and relative intensity in 3rd region in Fig. $1\left(360-380^{\circ} \mathrm{C}\right)$, shows the presence of a graphite-like structure, even though the relative intensity in the $\mathrm{C} 1 \mathrm{~s}$ spectra dropped significantly in the 4th region in Fig. 1. In addition, the gradual disappearance of the shake-up peaks $\left(\pi-\pi^{*}\right.$ transition, see Table 1$)$ is likely an alternative indication of the local benzene ring vanishing at temperatures above $280^{\circ} \mathrm{C}$. It may be stated that the relative intensity in the C1s spectra, the $\mathrm{LT}_{G R L}$ and the plasmon loss $\left(\Delta E_{\mathrm{L}}\right)$ are distinct factors that are indispensable for understanding the charring process.

\subsubsection{PIP}

Essential data for PIP are shown in Fig. 4, Fig. 5 and the data is tabulated in Table 4. A much lower relative intensity for PIP, than PCP, in C1s spectra, along with the presence of a negative region, ascribed to contamination ${ }^{[8]}$, is noted. The relative intensity does not exceed $10 \%$ at a temperature below $380^{\circ} \mathrm{C}$. The fact that plasmon loss $\left(\Delta E_{\mathrm{L}}\right)$ remains constant at about $22.0 \mathrm{eV}$ below $380^{\circ} \mathrm{C}$ indicates that there is little or no change in the extent of conjugation within the polymeric matrix. One can, therefore, conclude that very little crosslinking occurs until a temperature of $380^{\circ} \mathrm{C}$ is reached. 


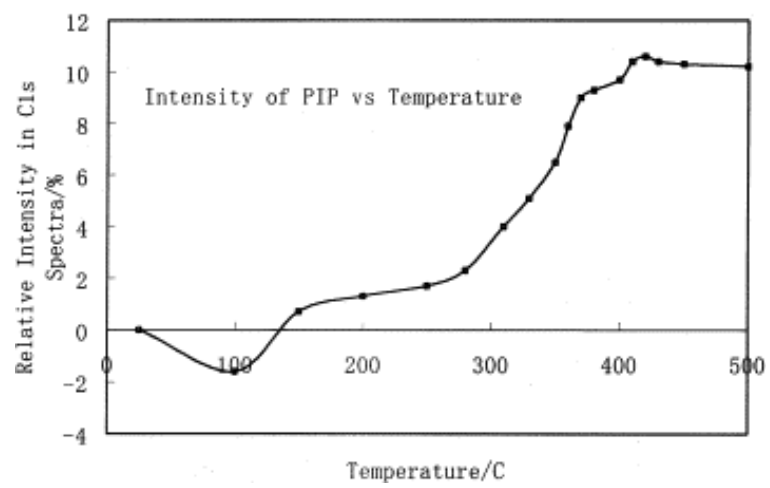

Fig. 4. Relative intensity (\%) of PIP vs temperature.

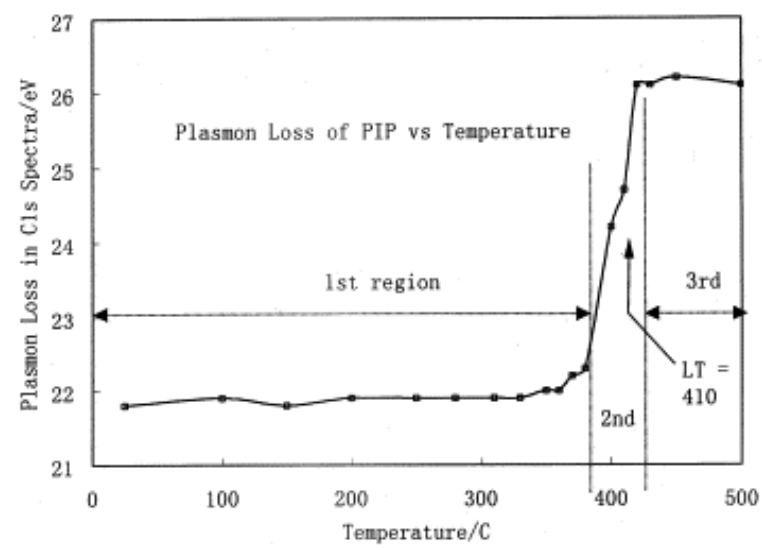

Fig. 5. Plasmon loss $\left(\Delta E_{\mathrm{L}}\right)$ of PIP vs temperature.

Table 4. XPS data for PIP thin film on Al foil

\begin{tabular}{|c|c|c|c|c|c|c|}
\hline Temperature & C1s & C1s & & Plasmon & $\Delta E_{\mathrm{L}}$ & Shake-up \\
\hline$\left({ }^{\circ} \mathrm{C}\right)$ & $(\mathrm{eV})$ & CPS & Intensity (\%) & $(\mathrm{eV})$ in C1s & $(e V)$ in C1s & (eV) \\
\hline 25 & 285.6 & 56820 & 0.0 & 307.4 & 21.8 & 292.2 \\
\hline 100 & 285.6 & 55890 & -1.6 & 307.5 & 21.9 & 292.2 \\
\hline 150 & 285.6 & 57240 & 0.7 & 307.4 & 21.8 & 292.3 \\
\hline 200 & 285.6 & 57570 & 1.3 & 307.5 & 21.9 & 292.3 \\
\hline 250 & 285.7 & 57810 & 1.7 & 307.6 & 21.9 & 292.2 \\
\hline 280 & 285.7 & 58120 & 2.3 & 307.6 & 21.9 & 292.1 \\
\hline 310 & 285.7 & 59080 & 4.0 & 307.6 & 21.9 & 292.2 \\
\hline 330 & 285.7 & 59720 & 5.1 & 307.6 & 21.9 & 292.2 \\
\hline 350 & 285.7 & 60520 & 6.5 & 307.7 & 22.0 & 292.3 \\
\hline 360 & 285.7 & 61290 & 7.9 & 307.7 & 22.0 & 292.2 \\
\hline 370 & 285.7 & 61910 & 9.0 & 307.9 & 22.2 & 292.0 \\
\hline 380 & 285.6 & 62120 & 9.3 & 307.9 & 22.3 & 292.0 \\
\hline 400 & 285.3 & 62330 & 9.7 & 309.5 & 24.2 & 292.0 \\
\hline 410 & 285.3 & 62740 & 10.4 & 310.0 & 24.7 & n.d.․․ \\
\hline 420 & 285.3 & 62820 & 10.6 & 311.4 & 26.1 & n.d. \\
\hline 430 & 285.3 & 62320 & 10.4 & 311.4 & 26.1 & n.d. \\
\hline 450 & 285.3 & 62660 & 10.3 & 311.5 & 26.2 & n.d. \\
\hline 500 & 285.3 & 62590 & 10.2 & 311.4 & 26.1 & n.d. \\
\hline
\end{tabular}

an.d.: not detectable.

This agrees well with the literature assertion ${ }^{[3]}$ that PIP does not easily cross-link during the course of thermogravimetric analysis. The very large increase in $\Delta E_{\mathrm{L}}$ from 22.0 to $26.0 \mathrm{eV}$, between $380-420^{\circ} \mathrm{C}$ reveals the 
emergence of the graphite-like structure which is defined by $L T_{G R L}=410^{\circ} \mathrm{C}$. In the 2 nd region, an increase in intensity of the $\mathrm{Cls}$ peak arises but, it is weak in comparison to that observed for PCP. The plasmon loss of $26.1 \mathrm{eV}$ at $420^{\circ} \mathrm{C}$ confirms the appearance of aromatics.

The data shown in Fig. 6 , Fig. 7 clearly show that the substitution of a hydrogen for a chlorine has a very important role in the cross-linking process and, ultimately, in fire retardancy of the polymer.

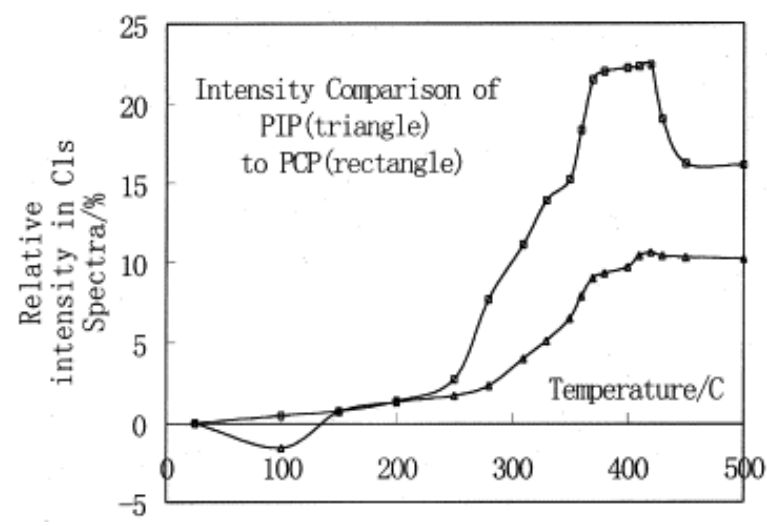

Fig. 6. Comparison of relative intensity between PIP and PCP.

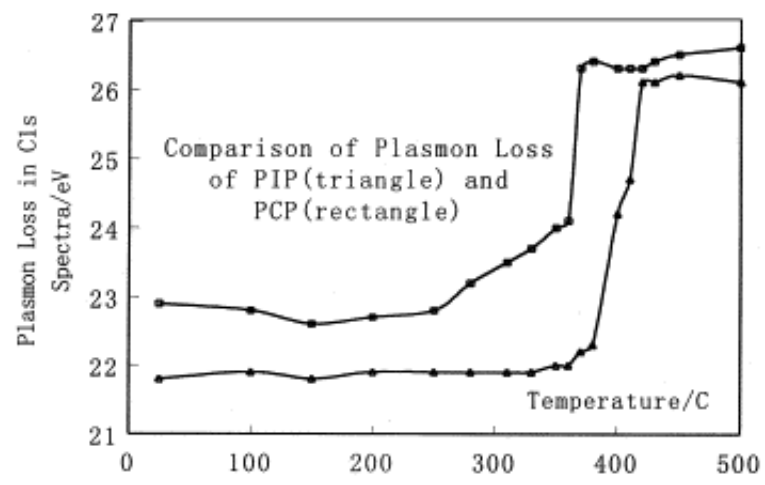

Fig. 7. Comparison of plasmon loss between PIP and PCP.

Apparently for both PCP and PIP, but particularly important for PCP, a large increase in the plasmon loss occurs within a very small temperature range, as seen in Fig. 7. Cross-linking and char formation for PCP proceed at an extremely high rate within a quite narrow temperature interval, $10^{\circ} \mathrm{C}$, and this must be related to the presence of the chlorine atom and the double bond. The PCP curve lies above the PIP curve and this indicates the important role that chlorine plays in cross-linking and char formation.

\subsection{Thermal degradation and charring of cross-linked PCP and PIP}

\subsubsection{PCP/BPO}

TGA data for both PIP and PCP are shown in Table 5 while Table 6 , Table 7, Table 8 , Table 9 provide the XPS data for PCP which has been cross-linked with BPO for times ranging from 3 to $24 \mathrm{~h}$. The main data can directly be depicted in Fig. 8, Fig. 9. The time of the cross-linking reaction apparently induces changes in the patterns in the plots of relative intensity vs temperature. On one hand a much stronger relative intensity, in contrast with original PCP, is seen in cross-linked samples at $70^{\circ} \mathrm{C}$ and times shorter than $6 \mathrm{~h}$. On the other hand a much weaker relative intensity relative to original $\mathrm{PCP}$ is seen in cross-linked samples at $70^{\circ} \mathrm{C}$ and times longer than say, $12 \mathrm{~h}$. 
Table 5. TGA/DTG data of chemically cross-linked PIP and PCP

\begin{tabular}{|c|c|c|c|c|c|c|}
\hline & & Peak $_{1}$ & & Peak $_{2}$ & & \\
\hline Polymers & $T_{10 \%}\left({ }^{\circ} \mathrm{C}\right)$ & $\left({ }^{\circ} \mathrm{C}\right)$ & (\%/min) & $\left({ }^{\circ} \mathrm{C}\right)$ & (\%/min) & $R_{500^{\circ} \mathrm{C}}(\%)$ \\
\hline PIP & 345.2 & 371.2 & 22.3 & - & & 0 \\
\hline PIP/BPO & 340.4 & 372.1 & 17.2 & - & & 1.7 \\
\hline PCP & 307.2 & 367.8 & 9.4 & 434.1 & 8.7 & 17.1 \\
\hline PCP/BPO & 266.3 & 354.1 & 5.6 & 445.4 & 6.0 & 26.5 \\
\hline
\end{tabular}

Table 6. XPS data on PCP/BPO at $70^{\circ} \mathrm{C}$ for $3 \mathrm{~h}$

\begin{tabular}{|c|c|c|c|c|c|}
\hline Temperature & C1s & C1s & & Plasmon & $\Delta E_{\mathrm{L}}$ \\
\hline$\left({ }^{\circ} \mathrm{C}\right)$ & C1s (eV) & CPS & Intensity (\%) & $(\mathrm{eV})$ & (eV) \\
\hline 25 & 285.9 & 38610 & 0.0 & 309.6 & 23.7 \\
\hline 100 & 285.8 & 38800 & 0.5 & 309.6 & 23.8 \\
\hline 150 & 286.5 & 38910 & 0.8 & 309.8 & 23.3 \\
\hline 200 & 286.0 & 39200 & 1.5 & 309.8 & 23.8 \\
\hline 250 & 285.7 & 41370 & 7.1 & 309.8 & 24.1 \\
\hline 280 & 285.5 & 41850 & 8.4 & 309.9 & 24.4 \\
\hline 310 & 285.2 & 45250 & 17.2 & 309.9 & 24.7 \\
\hline 340 & 284.9 & 45490 & 17.8 & 311.4 & 26.5 \\
\hline 370 & 284.7 & 46030 & 19.2 & 311.6 & 26.9 \\
\hline 400 & 284.7 & 46060 & 19.3 & 311.6 & 26.9 \\
\hline 430 & 284.8 & 46110 & 19.4 & 311.7 & 26.9 \\
\hline 460 & 284.9 & 46440 & 20.3 & 311.5 & 26.6 \\
\hline 500 & 284.9 & 46620 & 20.7 & 311.7 & 26.8 \\
\hline
\end{tabular}

Table 7. XPS data on PCP/BPO at $70^{\circ} \mathrm{C}$ for $6 \mathrm{~h}$

\begin{tabular}{|c|c|c|c|c|c|}
\hline Temperature & C1s & C1s & & Plasmon & $\Delta E_{\mathrm{L}}$ \\
\hline$\left({ }^{\circ} \mathrm{C}\right)$ & $(\mathrm{eV})$ & CPS & Intensity (\%) & $(\mathrm{eV})$ & (eV) \\
\hline 25 & 285.9 & 37060 & 0.0 & 309.5 & 23.6 \\
\hline 100 & 285.9 & 37330 & 0.7 & 309.4 & 23.5 \\
\hline 150 & 286.3 & 37500 & 1.2 & 309.5 & 23.2 \\
\hline 200 & 285.9 & 38370 & 3.5 & 309.5 & 23.6 \\
\hline 250 & 285.6 & 41260 & 11.3 & 309.7 & 24.1 \\
\hline 280 & 285.4 & 41700 & 12.5 & 309.7 & 24.3 \\
\hline 310 & 285.0 & 42710 & 15.2 & 309.7 & 24.7 \\
\hline 340 & 284.8 & 45270 & 22.1 & 311.1 & 26.3 \\
\hline 370 & 284.6 & 45600 & 23.0 & 311.5 & 26.9 \\
\hline 400 & 284.6 & 45850 & 23.7 & 311.5 & 26.9 \\
\hline 430 & 284.6 & 46100 & 24.4 & 311.6 & 27.0 \\
\hline 460 & 284.7 & 47080 & 27.0 & 311.7 & 27.0 \\
\hline 500 & 284.9 & 47390 & 27.9 & 311.7 & 26.8 \\
\hline
\end{tabular}

Table 8. XPS data on PCP/BPO at $70^{\circ} \mathrm{C}$ for $12 \mathrm{~h}$

\begin{tabular}{|l|c|c|l|c|c|}
\hline Temperature & C1s & C1s & & Plasmon & $\boldsymbol{\Delta} E_{\mathbf{L}}$ \\
\hline \multicolumn{1}{|c}{$\left.\mathbf{(}^{\circ} \mathbf{C}\right)$} & $\mathbf{( e V )}$ & CPS & Intensity $(\mathbf{\%})$ & $\mathbf{( e V )}$ & $(\mathbf{e V})$ \\
\hline 25 & 285.8 & 40980 & 0.0 & 309.6 & 23.8 \\
\hline 100 & 285.8 & 41040 & 0.2 & 309.5 & 23.7 \\
\hline
\end{tabular}




\begin{tabular}{|l|l|l|l|l|l|}
\hline 150 & 285.7 & 41740 & 1.9 & 309.7 & 24.0 \\
\hline 200 & 285.6 & 42040 & 2.6 & 309.7 & 24.1 \\
\hline 250 & 285.5 & 42110 & 2.8 & 309.6 & 24.1 \\
\hline 280 & 285.4 & 42820 & 4.5 & 309.7 & 24.3 \\
\hline 310 & 285.1 & 42920 & 4.7 & 310.0 & 24.9 \\
\hline 340 & 284.9 & 46250 & 12.9 & 311.1 & 26.2 \\
\hline 370 & 284.7 & 46670 & 13.9 & 311.2 & 26.5 \\
\hline 400 & 284.7 & 46800 & 14.2 & 311.3 & 26.6 \\
\hline 430 & 284.8 & 46930 & 14.5 & 311.3 & 26.5 \\
\hline 460 & 285.0 & 47070 & 14.9 & 311.2 & 26.2 \\
\hline 500 & 284.9 & 47170 & 15.1 & 311.3 & 26.4 \\
\hline
\end{tabular}

Table 9. XPS data on PCP/BPO at $70^{\circ} \mathrm{C}$ for $24 \mathrm{~h}$

\begin{tabular}{|l|c|c|l|l|l|}
\hline $\begin{array}{c}\text { Temperature } \\
\left({ }^{\circ} \mathbf{C}\right)\end{array}$ & $\begin{array}{c}\text { C1s } \\
(\mathbf{e V})\end{array}$ & $\begin{array}{c}\text { C1s } \\
\text { CPS }\end{array}$ & Intensity $(\%)$ & $\begin{array}{c}\text { Plasmon } \\
(\mathbf{e V})\end{array}$ & $\begin{array}{c}\Delta E_{\mathbf{L}} \\
(\mathbf{e V})\end{array}$ \\
\hline 25 & 285.8 & 40560 & 0.0 & 310.2 & 24.4 \\
\hline 100 & 285.7 & 40620 & 0.1 & 310.2 & 24.5 \\
\hline 150 & 285.7 & 40770 & 0.5 & 310.1 & 24.4 \\
\hline 200 & 285.7 & 40820 & 0.6 & 310.3 & 24.6 \\
\hline 250 & 285.5 & 41800 & 3.1 & 310.2 & 24.7 \\
\hline 280 & 285.3 & 42010 & 3.6 & 310.3 & 25.0 \\
\hline 310 & 285.2 & 42240 & 4.2 & 310.2 & 25.0 \\
\hline 340 & 284.9 & 44500 & 9.7 & 310.2 & 25.3 \\
\hline 370 & 284.7 & 45720 & 12.7 & 311.2 & 26.5 \\
\hline 400 & 284.6 & 45790 & 12.9 & 311.3 & 26.7 \\
\hline 430 & 284.7 & 45840 & 13.0 & 311.6 & 26.9 \\
\hline 460 & 284.9 & 45897 & 13.2 & 311.6 & 26.7 \\
\hline 500 & 285.0 & 45970 & 13.3 & 311.4 & 26.4 \\
\hline & & & & & \\
\hline
\end{tabular}

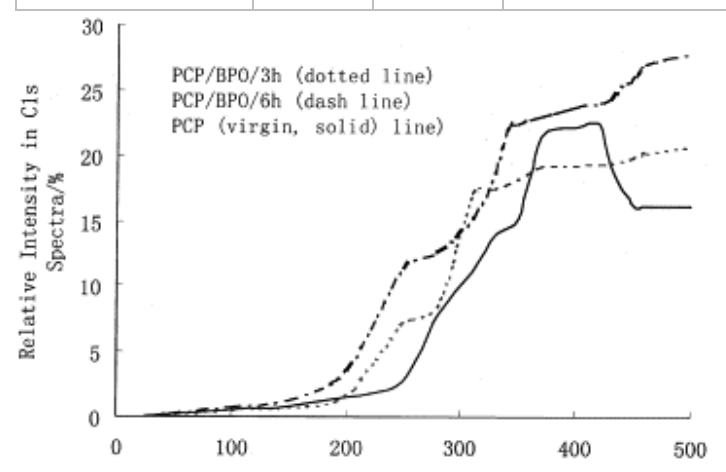

Fig. 8. Relative intensity of PCP/BPO heated in an oil bath at $70^{\circ} \mathrm{C}$ for 3 (dotted line) and $6 \mathrm{~h}$ (dash line).

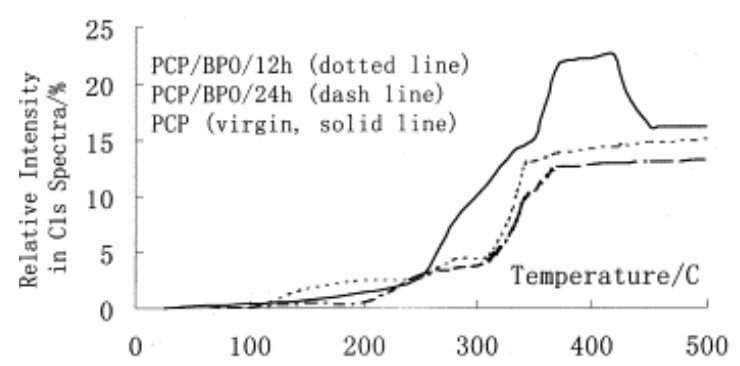

Fig. 9. Relative intensity of $\mathrm{PCP} / \mathrm{BPO}$ heated in an oil bath at $70^{\circ} \mathrm{C}$ for 12 (dotted line) and $24 \mathrm{~h}$ (dash line). 


\subsubsection{XPS data on percentage of chlorine in PCP vs temperature}

The XPS data which relates the amount of chlorine remaining to temperature is collected in Table 10. The loss of chlorine in both cross-linked and virgin polymer begins at about $200^{\circ} \mathrm{C}$ but the cross-linked systems lose chlorine much more readily. At $370^{\circ} \mathrm{C}$ the cross-linked polymers retain more chlorine than does the virgin material. This is presumably due to the rigidity of the cross-linked system preventing the facile loss of chlorine.

Table 10. Percentage of chlorine remaining in PCP vs temperature $\mathrm{a}^{\mathrm{a}}$

\begin{tabular}{|c|c|c|c|c|c|c|c|c|c|c|}
\hline $\begin{array}{c}\text { Temperat } \\
\text { ure }\end{array}$ & $\begin{array}{c}\text { PCP } \\
\text { Virgi } \\
n\end{array}$ & & $\begin{array}{c}\mathrm{PCP} / \mathrm{BPO} / \\
3 \mathrm{~h}\end{array}$ & & $\begin{array}{c}\text { PCP/BPO/ } \\
6 \mathrm{~h}\end{array}$ & & $\begin{array}{c}\text { PCP/BPO/ } \\
12 \mathrm{~h}\end{array}$ & & $\begin{array}{c}\text { PCP/BPO/ } \\
24 \mathrm{~h}\end{array}$ & \\
\hline$\left({ }^{\circ} \mathrm{C}\right)$ & CPS & $\begin{array}{l}\text { Intensi } \\
\text { ty (\%) }\end{array}$ & CPS & $\begin{array}{l}\text { Intensi } \\
\text { ty (\%) }\end{array}$ & CPS & $\begin{array}{l}\text { Intensi } \\
\text { ty (\%) }\end{array}$ & CPS & $\begin{array}{l}\text { Intensi } \\
\text { ty (\%) }\end{array}$ & CPS & $\begin{array}{l}\text { Intensi } \\
\text { ty (\%) }\end{array}$ \\
\hline 25 & $\begin{array}{l}200 \\
70\end{array}$ & 100.0 & 7060 & 100.0 & 6670 & 100.0 & 6630 & 100.0 & 4630 & 100.0 \\
\hline 100 & $\begin{array}{l}198 \\
60\end{array}$ & 99.0 & 7060 & 100.0 & 6630 & 99.4 & 6570 & 99.1 & 4610 & 99.6 \\
\hline 200 & $\begin{array}{l}178 \\
50\end{array}$ & 89.0 & 4130 & 58.5 & 3850 & 57.8 & 4500 & 67.8 & 3100 & 66.9 \\
\hline 310 & $\begin{array}{l}374 \\
0\end{array}$ & 18.6 & 880 & 12.5 & 2150 & 32.2 & 800 & 12.1 & 680 & 14.7 \\
\hline 370 & 100 & 0.5 & 220 & 3.1 & 200 & 3.1 & 190 & 2.9 & 210 & 4.5 \\
\hline
\end{tabular}

aRelative intensity (\%) in C12p spectra as function of temperature for PCP.

\subsubsection{PIP/BPO}

Table 11, Table 12, Table 13, Table 14 give the XPS data for systems of PIP modified with BPO at $70^{\circ} \mathrm{C}$ for time period 3-24 h. A summation of all of the above data is provided in Fig. 10, Fig. 11. There is a strong change in the relative intensity as a function of reaction time, indicating the strong dependence of cross-linking on this parameter. Cross-linking does not occur with virgin PIP to any significant extent upon heating but, in the samples containing BPO, there is a very significant amount of cross-linking with a short reaction time. This will be discussed later in the text.

Table 11. XPS data on PIP/BPO at $70^{\circ} \mathrm{C}$ for $3 \mathrm{~h}$

\begin{tabular}{|c|c|c|c|c|c|}
\hline Temperature & C1s & C1s & & Plasmon & $\Delta E_{\mathrm{L}}$ \\
\hline$\left({ }^{\circ} \mathrm{C}\right)$ & $(e V)$ & CPS & Intensity (\%) & $(\mathrm{eV})$ & (eV) \\
\hline 25 & 286.5 & 13790 & 0.0 & 308.6 & 21.1 \\
\hline 100 & 286.3 & 14710 & 6.7 & 308.6 & 22.3 \\
\hline 150 & 286.3 & 15740 & 14.1 & 308.7 & 22.4 \\
\hline 200 & 286.2 & 16120 & 16.9 & 308.7 & 22.5 \\
\hline 250 & 286.2 & 16090 & 16.7 & 308.8 & 22.6 \\
\hline 280 & 286.2 & 16180 & 17.3 & 308.8 & 22.6 \\
\hline 310 & 286.1 & 19500 & 41.4 & 308.8 & 22.7 \\
\hline 340 & 285.9 & 19610 & 42.2 & 308.7 & 22.8 \\
\hline 370 & 285.6 & 21280 & 54.3 & 308.9 & 23.6 \\
\hline 400 & 285.3 & 23130 & 67.7 & 310.3 & 25.0 \\
\hline 430 & 285.1 & 23360 & 69.4 & 310.4 & 25.3 \\
\hline 460 & 285.2 & 23450 & 70.0 & 310.5 & 25.3 \\
\hline 500 & 285.5 & 23520 & 70.5 & 311.0 & 25.5 \\
\hline
\end{tabular}


Table 12. XPS data on PIP/BPO at $70^{\circ} \mathrm{C}$ for $6 \mathrm{~h}$

\begin{tabular}{|c|c|c|c|c|c|}
\hline Temperature & C1s & C1s & & Plasmon & $\Delta E_{\mathrm{L}}$ \\
\hline$\left({ }^{\circ} \mathrm{C}\right)$ & $(e V)$ & CPS & Intensity (\%) & (eV) & $(\mathrm{eV})$ \\
\hline 25 & 286.3 & 14560 & 0.0 & 308.7 & 22.4 \\
\hline 100 & 286.1 & 14880 & 6.7 & 308.7 & 22.6 \\
\hline 150 & 286.1 & 15760 & 14.1 & 308.8 & 22.7 \\
\hline 200 & 286.1 & 16410 & 16.9 & 308.8 & 22.7 \\
\hline 250 & 286.1 & 15090 & 16.7 & 308.8 & 22.7 \\
\hline 280 & 286.0 & 17300 & 17.3 & 308.9 & 22.9 \\
\hline 310 & 286.0 & 19630 & 41.4 & 308.8 & 22.8 \\
\hline 340 & 285.8 & 20130 & 42.2 & 308.8 & 23.0 \\
\hline 370 & 285.6 & 20610 & 54.3 & 308.8 & 23.2 \\
\hline 400 & 285.4 & 21390 & 46.9 & 309.9 & 24.5 \\
\hline 430 & 285.0 & 22190 & 52.4 & 310.0 & 25.0 \\
\hline 460 & 284.8 & 23220 & 59.4 & 310.4 & 25.6 \\
\hline 500 & 285.3 & 23570 & 61.8 & 311.4 & 26.1 \\
\hline
\end{tabular}

Table 13. XPS data on PIP/BPO at $70^{\circ} \mathrm{C}$ for $12 \mathrm{~h}$

\begin{tabular}{|l|c|c|l|l|l|}
\hline $\begin{array}{l}\text { Temperature } \\
\left.\mathbf{(}{ }^{\circ} \mathbf{C}\right)\end{array}$ & $\begin{array}{c}\text { C1s } \\
(\mathbf{e V})\end{array}$ & $\begin{array}{c}\text { C1s } \\
\text { CPS }\end{array}$ & Intensity $\mathbf{( \% )}$ & $\begin{array}{c}\text { Plasmon } \\
\mathbf{( e V )}\end{array}$ & $\begin{array}{c}\boldsymbol{\Delta} \boldsymbol{E}_{\mathbf{L}} \\
\mathbf{( e V})\end{array}$ \\
\hline 25 & 285.6 & 40860 & 0.0 & 308.0 & 22.4 \\
\hline 100 & 285.5 & 41360 & 1.2 & 308.1 & 22.6 \\
\hline 150 & 285.5 & 41420 & 1.4 & 308.1 & 22.6 \\
\hline 200 & 285.5 & 41610 & 1.8 & 307.9 & 22.4 \\
\hline 250 & 285.5 & 41920 & 2.6 & 308.0 & 22.5 \\
\hline 280 & 285.4 & 42050 & 2.9 & 308.1 & 22.7 \\
\hline 310 & 285.4 & 42310 & 3.6 & 308.1 & 22.7 \\
\hline 340 & 285.3 & 42410 & 3.8 & 308.1 & 22.8 \\
\hline 370 & 285.1 & 42840 & 4.9 & 308.1 & 23.0 \\
\hline 400 & 284.7 & 47260 & 15.7 & 309.0 & 24.3 \\
\hline 430 & 284.5 & 48307 & 18.2 & 309.8 & 25.3 \\
\hline 460 & 284.7 & 49670 & 21.6 & 310.1 & 25.4 \\
\hline 500 & 284.9 & 49870 & 22.1 & 310.1 & 25.2 \\
\hline
\end{tabular}

Table 14. XPS data on PIP/BPO at $70^{\circ} \mathrm{C}$ for $24 \mathrm{~h}$

\begin{tabular}{|c|c|c|c|c|c|}
\hline Temperature & C1s & C1s & & Plasmon & $\Delta E_{\mathrm{L}}$ \\
\hline$\left({ }^{\circ} \mathrm{C}\right)$ & $(\mathrm{eV})$ & CPS & Intensity (\%) & $(\mathrm{eV})$ & (eV) \\
\hline 25 & 285.3 & 28210 & 0.0 & 308.0 & 22.7 \\
\hline 100 & 285.3 & 28440 & 0.5 & 308.0 & 22.7 \\
\hline 150 & 285.2 & 28900 & 2.4 & 308.1 & 22.9 \\
\hline 200 & 285.2 & 28970 & 2.7 & 308.1 & 22.9 \\
\hline 250 & 285.3 & 29050 & 3.0 & 308.0 & 22.7 \\
\hline 280 & 285.3 & 29050 & 3.0 & 308.0 & 22.7 \\
\hline 310 & 285.3 & 29170 & 3.0 & 308.2 & 22.9 \\
\hline 340 & 285.3 & 29190 & 3.1 & 308.3 & 23.0 \\
\hline 370 & 285.3 & 29420 & 4.3 & 308.9 & 23.6 \\
\hline 400 & 285.1 & 32070 & 13.7 & 309.0 & 23.9 \\
\hline 430 & 284.9 & 32120 & 13.8 & 309.1 & 24.2 \\
\hline
\end{tabular}




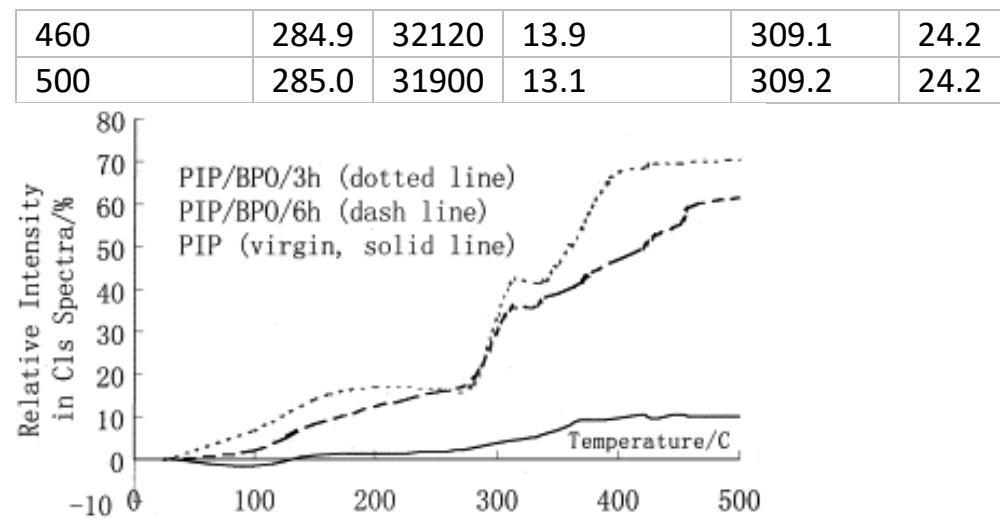

Fig. 10. Relative intensity of PIP/BPO heated in an oil bath at $70^{\circ} \mathrm{C}$ for 3 (dotted line) and $6 \mathrm{~h}$ (dash line).

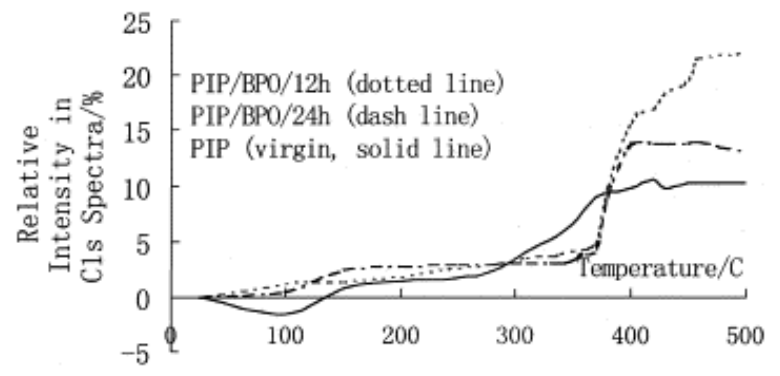

Fig. 11. Relative intensity of PIP/BPO heated in an oil bath at $70^{\circ} \mathrm{C}$ for 12 (dotted line) and $24 \mathrm{~h}$ (dash line).

\subsubsection{Comparison between PCP and PIP chemically cross-linked by BPO}

There is a significant difference in the extent of cross-linking between PCP and PIP; this is shown in Fig. 12, Fig. 13, Fig. 14, Fig. 15. For reaction times of 3 and $6 \mathrm{~h}$, the retention of carbon is much greater for PIP than for PCP, indicating that the cross-linked PIP samples with BPO can more easily lose other elements than does PCP. At longer reaction times, there is more similarity between PIP and PCP.

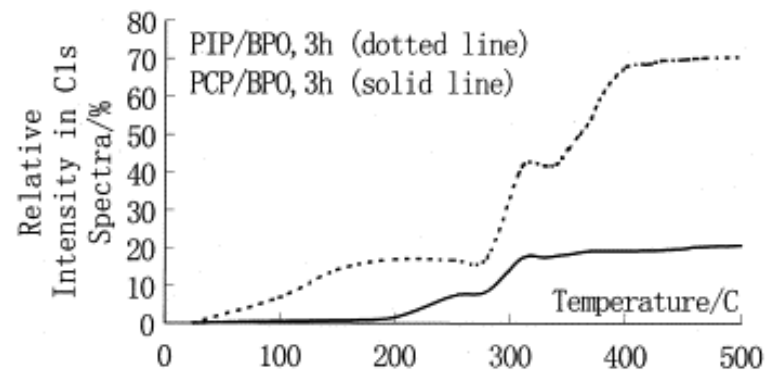

Fig. 12. Relative intensity of PIP/BPO (dotted line) and PCP/BPO (solid line) heated in an oil bath at $70^{\circ} \mathrm{C}$ for $3 \mathrm{~h}$.

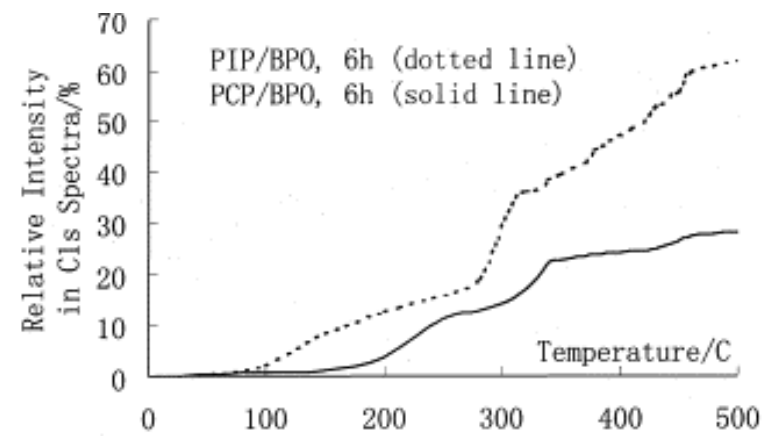

Fig. 13. Relative intensity of PIP/BPO (dotted line) and PCP/BPO (solid line) heated in an oil bath at $70^{\circ} \mathrm{C}$ for $6 \mathrm{~h}$. 


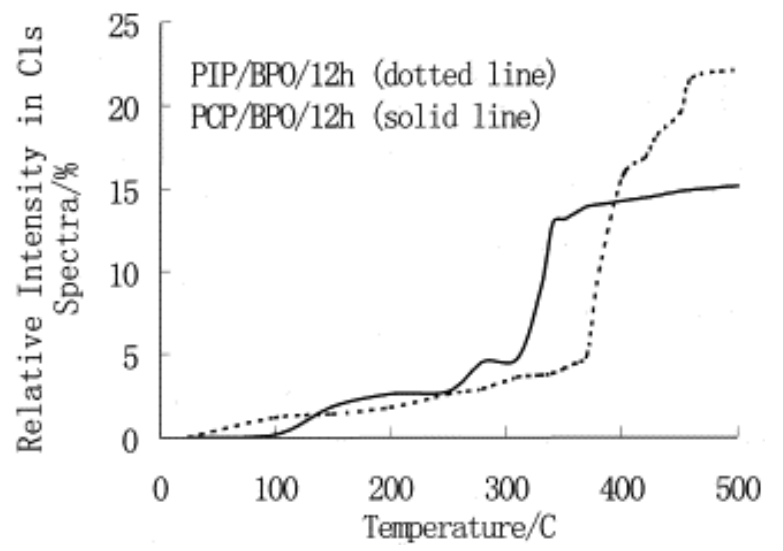

Fig. 14. Relative intensity of PIP/BPO (dotted line) and PCP/BPO (solid line) heated in an oil bath at $70^{\circ} \mathrm{C}$ for $12 \mathrm{~h}$.

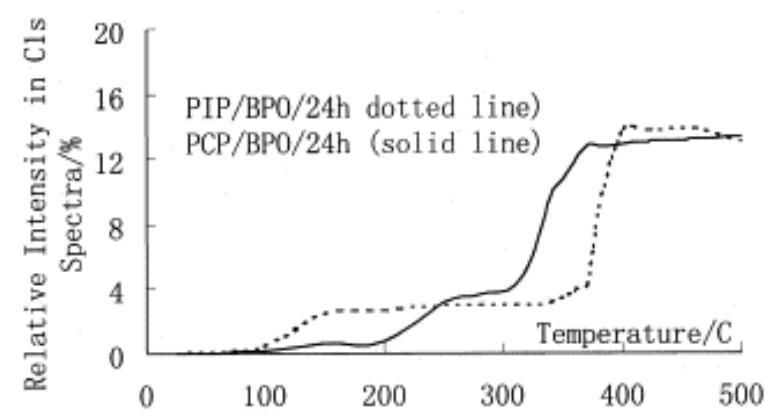

Fig. 15. Relative intensity of PIP/BPO/24 h (dotted line) and PCP/BPO/24 h (solid line).

\subsubsection{XPS data for PCP/PIP chemically cross-linked with DCP}

The differences between PCP and PIP as a function of reaction time are shown in Fig. 16, Fig. 17; the tabular data for PCP modified with DCP is shown in Table 15, Table 16, Table 17, Table 18 while the data for the PIP system is in Table 19, Table 20, Table 21, Table 22.

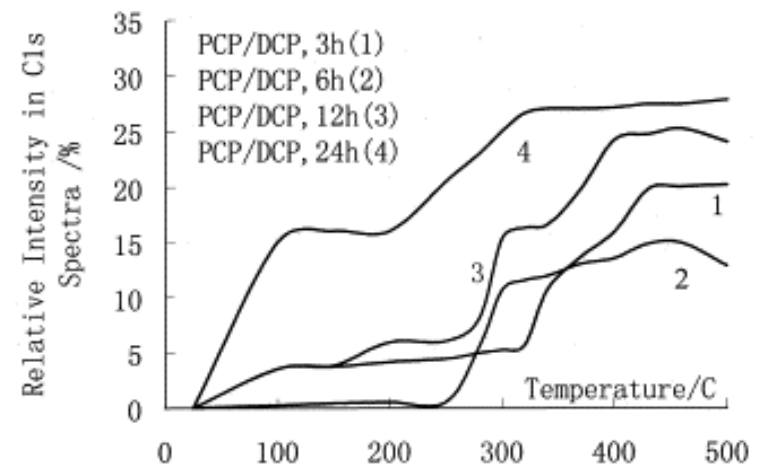

Fig. 16. Relative intensity of PCP/DCP heated in an oil bath at $120^{\circ} \mathrm{C}$ for $3,6,12,24 \mathrm{~h}$ separately. 


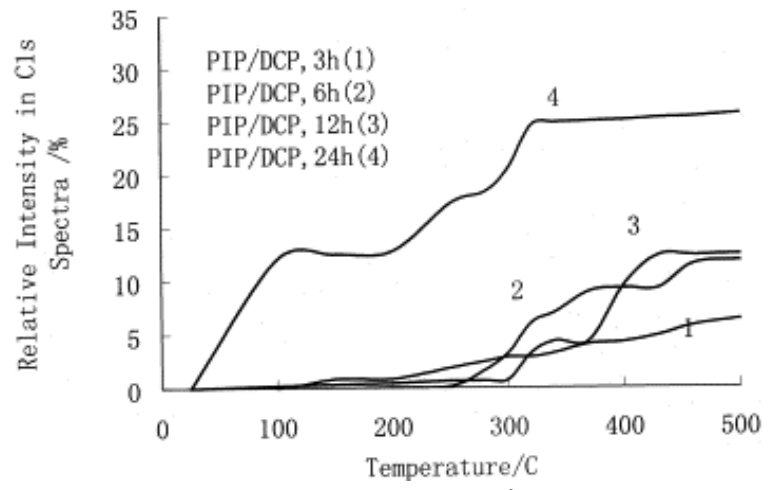

Fig. 17. Relative intensity of PIP/DCP heated in an oil bath at $120^{\circ} \mathrm{C}$ for $3,6,12,24 \mathrm{~h}$ separately.

Table 15. XPS data on PCP/DCP at $120^{\circ} \mathrm{C}$ for $3 \mathrm{~h}$

\begin{tabular}{|c|c|c|c|c|c|}
\hline Temperature & C1s & C1s & & Plasmon & $\Delta E_{\mathrm{L}}$ \\
\hline$\left({ }^{\circ} \mathrm{C}\right)$ & (eV) & CPS & Intensity (\%) & (eV) & (eV) \\
\hline 25 & 286.4 & 36630 & 0.0 & 309.7 & 23.3 \\
\hline 100 & 286.4 & 37920 & 3.5 & 309.8 & 23.4 \\
\hline 150 & 286.4 & 38000 & 3.7 & 309.8 & 23.4 \\
\hline 200 & 286.2 & 38120 & 4.1 & 309.8 & 23.6 \\
\hline 250 & 286.1 & 38230 & 4.4 & 309.8 & 23.7 \\
\hline 280 & 285.9 & 38430 & 4.9 & 309.8 & 23.9 \\
\hline 300 & 285.7 & 38540 & 5.2 & 309.9 & 24.2 \\
\hline 320 & 285.6 & 38690 & 5.6 & 309.9 & 24.3 \\
\hline 340 & 285.4 & 40550 & 10.7 & 310.8 & 25.4 \\
\hline 370 & 285.1 & 41620 & 13.6 & 310.9 & 25.8 \\
\hline 400 & 284.7 & 42450 & 15.9 & 312.2 & 27.5 \\
\hline 430 & 284.7 & 43890 & 19.8 & 312.2 & 27.5 \\
\hline
\end{tabular}

Table 16. XPS data on PCP/DCP at $120^{\circ} \mathrm{C}$ for $6 \mathrm{~h}$

\begin{tabular}{|l|c|l|l|l|l|}
\hline $\begin{array}{c}\text { Temperature } \\
\left.\mathbf{(}{ }^{\circ} \mathbf{C}\right)\end{array}$ & $\begin{array}{c}\text { C1s } \\
(\mathbf{e V})\end{array}$ & $\begin{array}{c}\text { C1s } \\
\text { CPS }\end{array}$ & Intensity (\%) & $\begin{array}{c}\text { Plasmon } \\
(\mathbf{e V})\end{array}$ & $\begin{array}{c}\boldsymbol{\Delta} \boldsymbol{E}_{\mathbf{L}} \\
\mathbf{( e V )}\end{array}$ \\
\hline 25 & 286.3 & 39140 & 0.0 & 309.5 & 23.2 \\
\hline 100 & 286.3 & 39230 & 0.2 & 309.6 & 23.3 \\
\hline 150 & 286.2 & 39300 & 0.4 & 309.5 & 23.3 \\
\hline 200 & 286.1 & 39320 & 0.5 & 309.6 & 23.5 \\
\hline 250 & 285.9 & 39330 & 0.5 & 309.7 & 23.8 \\
\hline 280 & 285.7 & 41290 & 5.5 & 309.6 & 23.9 \\
\hline 300 & 285.6 & 43270 & 10.6 & 309.6 & 24.0 \\
\hline 320 & 285.4 & 43660 & 11.5 & 309.6 & 24.2 \\
\hline 340 & 285.4 & 43800 & 11.9 & 309.6 & 24.2 \\
\hline 370 & 285.0 & 44230 & 13.0 & 311.5 & 26.5 \\
\hline 400 & 284.6 & 44430 & 13.5 & 311.7 & 27.1 \\
\hline 430 & 284.8 & 44920 & 14.8 & 311.7 & 26.9 \\
\hline 460 & 284.9 & 44980 & 14.9 & 311.7 & 26.8 \\
\hline 500 & 284.9 & 44140 & 12.8 & 311.7 & 26.8 \\
\hline
\end{tabular}


Table 17. XPS data on PCP/DCP at $120^{\circ} \mathrm{C}$ for $12 \mathrm{~h}$

\begin{tabular}{|l|c|c|l|l|l|}
\hline $\begin{array}{c}\text { Temperature } \\
\left({ }^{\circ} \mathbf{C}\right)\end{array}$ & $\begin{array}{c}\text { C1s } \\
(\mathbf{e V})\end{array}$ & $\begin{array}{c}\text { C1s } \\
\text { CPS }\end{array}$ & Intensity $\mathbf{( \% )}$ & $\begin{array}{c}\text { Plasmon } \\
(\mathbf{e V})\end{array}$ & $\begin{array}{c}\Delta \boldsymbol{E}_{\mathbf{L}} \\
\mathbf{( e V )}\end{array}$ \\
\hline 25 & 286.3 & 36070 & 0.0 & 310.3 & 24.0 \\
\hline 100 & 286.3 & 37340 & 3.5 & 310.3 & 24.0 \\
\hline 150 & 286.3 & 37440 & 3.8 & 310.4 & 24.1 \\
\hline 200 & 286.1 & 38190 & 5.9 & 310.4 & 24.3 \\
\hline 250 & 285.9 & 38230 & 6.0 & 310.4 & 24.5 \\
\hline 280 & 285.7 & 38250 & 6.0 & 310.6 & 24.9 \\
\hline 300 & 285.6 & 41600 & 15.3 & 310.7 & 25.1 \\
\hline 320 & 285.4 & 41950 & 16.3 & 310.7 & 25.3 \\
\hline 340 & 285.3 & 42040 & 16.6 & 310.7 & 25.4 \\
\hline 370 & 285.0 & 43210 & 19.8 & 310.7 & 25.7 \\
\hline 400 & 284.6 & 44800 & 24.2 & 312.0 & 27.4 \\
\hline 430 & 284.6 & 44990 & 24.7 & 312.0 & 27.4 \\
\hline 460 & 284.8 & 45150 & 25.2 & 311.8 & 27.0 \\
\hline 500 & 285.0 & 44720 & 24.0 & 312.0 & 27.0 \\
\hline
\end{tabular}

Table 18. XPS data on PCP/DCP at $120^{\circ} \mathrm{C}$ for $24 \mathrm{~h}$

\begin{tabular}{|l|c|c|l|l|l|}
\hline $\begin{array}{c}\text { Temperature } \\
\left.\mathbf{(}{ }^{\circ} \mathbf{C}\right)\end{array}$ & $\begin{array}{c}\text { C1s } \\
(\mathbf{e V})\end{array}$ & \multicolumn{1}{|c|}{ C1s } & Intensity (\%) & $\begin{array}{c}\text { Plasmon } \\
(\mathbf{e V})\end{array}$ & $\begin{array}{c}\boldsymbol{\Delta} \boldsymbol{E}_{\mathbf{L}} \\
\mathbf{( e V )}\end{array}$ \\
\hline 25 & 286.3 & 33930 & 0.0 & 310.8 & 24.5 \\
\hline 100 & 286.2 & 38200 & 12.6 & 310.8 & 24.6 \\
\hline 150 & 286.3 & 38410 & 13.2 & 310.8 & 24.5 \\
\hline 200 & 286.2 & 38510 & 13.5 & 310.9 & 24.7 \\
\hline 250 & 285.9 & 39620 & 16.8 & 310.9 & 25.0 \\
\hline 280 & 285.8 & 40380 & 19.0 & 310.9 & 25.1 \\
\hline 300 & 285.6 & 41060 & 21.0 & 310.9 & 25.3 \\
\hline 320 & 285.4 & 41410 & 22.0 & 310.9 & 25.5 \\
\hline 340 & 285.3 & 41510 & 22.3 & 310.9 & 25.6 \\
\hline 370 & 285.1 & 42610 & 25.6 & 310.9 & 25.8 \\
\hline 400 & 284.6 & 43470 & 28.1 & 311.5 & 26.9 \\
\hline 430 & 284.6 & 43770 & 29.0 & 311.5 & 26.9 \\
\hline 460 & 284.9 & 43900 & 29.4 & 311.9 & 27.0 \\
\hline 500 & 284.8 & 43930 & 29.5 & 311.9 & 27.1 \\
\hline
\end{tabular}

Table 19. XPS data on PIP/DCP at $120^{\circ} \mathrm{C}$ for $3 \mathrm{~h}$

\begin{tabular}{|c|c|c|c|c|c|}
\hline Temperature & C1s & C1s & & Plasmon & $\Delta E_{\mathrm{L}}$ \\
\hline$\left({ }^{\circ} \mathrm{C}\right)$ & $(\mathrm{eV})$ & CPS & Intensity (\%) & $(\mathrm{eV})$ & (eV) \\
\hline 25 & 285.6 & 41010 & 0.0 & 307.3 & 21.7 \\
\hline 100 & 285.6 & 41020 & 0.0 & 307.4 & 21.8 \\
\hline 150 & 285.6 & 41340 & 0.8 & 307.3 & 21.7 \\
\hline 200 & 285.6 & 41350 & 0.8 & 307.3 & 21.7 \\
\hline 250 & 285.5 & 41730 & 1.8 & 307.3 & 21.8 \\
\hline 280 & 285.5 & 41990 & 2.4 & 307.4 & 21.9 \\
\hline 300 & 285.4 & 42170 & 2.8 & 307.4 & 22.0 \\
\hline 320 & 285.4 & 42180 & 2.8 & 307.6 & 22.2 \\
\hline 340 & 285.3 & 42320 & 3.2 & 307.9 & 22.6 \\
\hline
\end{tabular}




\begin{tabular}{|l|l|l|l|l|l|}
\hline 370 & 285.4 & 42640 & 4.0 & 308.3 & 22.9 \\
\hline 400 & 285.3 & 42750 & 4.2 & 308.7 & 23.4 \\
\hline 430 & 284.7 & 42960 & 4.8 & 309.4 & 24.7 \\
\hline 460 & 284.5 & 43340 & 5.7 & 309.6 & 25.1 \\
\hline 500 & 284.5 & 43600 & 6.3 & 309.6 & 25.1 \\
\hline
\end{tabular}

Table 20. XPS data on PIP/DC $P$ at $120^{\circ} \mathrm{C}$ for $6 \mathrm{~h}$

\begin{tabular}{|c|c|c|c|c|c|}
\hline Temperature & C1s & C1s & & Plasmon & $\Delta E_{\mathrm{L}}$ \\
\hline$\left({ }^{\circ} \mathrm{C}\right)$ & (eV) & CPS & Intensity (\%) & (eV) & $(\mathrm{eV})$ \\
\hline 25 & 285.7 & 39600 & 0.0 & 307.9 & 22.2 \\
\hline 100 & 285.7 & 39570 & -0.1 & 308.1 & 22.4 \\
\hline 150 & 285.7 & 39580 & -0.1 & 308.1 & 22.4 \\
\hline 200 & 285.7 & 39590 & 0.0 & 308.1 & 22.4 \\
\hline 250 & 285.7 & 39630 & 0.1 & 308.1 & 22.4 \\
\hline 280 & 285.7 & 40250 & 1.6 & 308.3 & 22.6 \\
\hline 300 & 285.6 & 40880 & 3.2 & 308.4 & 22.8 \\
\hline 320 & 285.6 & 41980 & 6.0 & 308.4 & 22.8 \\
\hline 340 & 285.6 & 42370 & 7.0 & 308.5 & 22.9 \\
\hline 370 & 285.6 & 43120 & 8.9 & 308.5 & 22.9 \\
\hline 400 & 285.5 & 43240 & 9.2 & 309.1 & 23.6 \\
\hline 430 & 284.9 & 43240 & 9.2 & 309.2 & 24.3 \\
\hline 460 & 284.5 & 44110 & 11.4 & 309.5 & 25.0 \\
\hline 500 & 284.6 & 44230 & 11.7 & 310.3 & 25.7 \\
\hline
\end{tabular}

Table 21. XPS data on PIP/DCP at $120^{\circ} \mathrm{C}$ for $12 \mathrm{~h}$

\begin{tabular}{|c|c|c|c|c|c|}
\hline Temperature & C1s & C1s & & Plasmon & $\Delta E_{\mathrm{L}}$ \\
\hline$\left({ }^{\circ} \mathrm{C}\right)$ & $(e V)$ & CPS & Intensity (\%) & (eV) & (eV) \\
\hline 25 & 285.7 & 39110 & 0.0 & 307.7 & 22.0 \\
\hline 100 & 285.6 & 39180 & 0.2 & 307.7 & 22.1 \\
\hline 150 & 285.6 & 39220 & 0.3 & 307.6 & 22.0 \\
\hline 200 & 285.7 & 39280 & 0.4 & 307.7 & 22.0 \\
\hline 250 & 285.6 & 39340 & 0.6 & 307.7 & 22.1 \\
\hline 280 & 285.6 & 39340 & 0.6 & 307.7 & 22.1 \\
\hline 300 & 285.7 & 39400 & 0.7 & 308.0 & 22.3 \\
\hline 320 & 285.6 & 40360 & 3.2 & 308.1 & 22.5 \\
\hline 340 & 285.6 & 40790 & 4.3 & 308.1 & 22.5 \\
\hline 370 & 285.7 & 40810 & 4.3 & 309.0 & 23.3 \\
\hline 400 & 285.6 & 42820 & 9.5 & 309.0 & 23.4 \\
\hline 430 & 285.0 & 43870 & 12.2 & 309.1 & 24.1 \\
\hline 460 & 284.7 & 43890 & 12.2 & 309.5 & 24.8 \\
\hline 500 & 284.6 & 43900 & 12.3 & 309.8 & 25.2 \\
\hline
\end{tabular}

Table 22. XPS data on PIP/DCP at $120^{\circ} \mathrm{C}$ for $24 \mathrm{~h}$

\begin{tabular}{|c|c|c|c|c|c|}
\hline Temperature & C1s & C1s & & Plasmon & $\Delta E_{\mathrm{L}}$ \\
\hline$\left({ }^{\circ} \mathrm{C}\right)$ & (eV) & CPS & Intensity (\%) & (eV) & $(e V)$ \\
\hline 25 & 285.9 & 34080 & 0.0 & 308.2 & 22.3 \\
\hline 100 & 285.9 & 38200 & 12.0 & 308.2 & 22.3 \\
\hline 150 & 285.9 & 38320 & 12.4 & 308.3 & 22.4 \\
\hline
\end{tabular}




\begin{tabular}{|l|l|l|l|l|l|}
\hline 200 & 285.8 & 38420 & 12.7 & 308.3 & 22.5 \\
\hline 250 & 285.9 & 39960 & 17.2 & 308.3 & 22.4 \\
\hline 280 & 285.8 & 40320 & 18.3 & 308.4 & 22.6 \\
\hline 300 & 285.7 & 41070 & 20.5 & 308.4 & 22.7 \\
\hline 320 & 285.7 & 42430 & 24.5 & 308.5 & 22.8 \\
\hline 340 & 285.6 & 42550 & 24.8 & 308.5 & 22.9 \\
\hline 370 & 285.6 & 42560 & 24.9 & 309.7 & 24.1 \\
\hline 400 & 285.5 & 42600 & 25.0 & 309.7 & 24.2 \\
\hline 430 & 284.8 & 42680 & 25.2 & 311.0 & 26.2 \\
\hline 460 & 284.5 & 42710 & 25.3 & 310.6 & 26.1 \\
\hline 500 & 284.6 & 42810 & 25.6 & 310.8 & 26.2 \\
\hline
\end{tabular}

The first analysis can be based upon relative intensity: A comparison of the influence of the reaction time on the maximum relative intensity, $I_{\max }$, for cross-linked PCP and PIP is shown in Table 23 . It is valuable to make a few observations. The maximum relative intensity, $I_{\max },(70.5 \%)$ observed for PIP must be contrasted to the value (20.7\%) observed for PCP in the presence of BPO at $3 \mathrm{~h}$ reaction time, even though PCP does give a higher intensity in the absence of initiators. This is not observed for DCP and this implies that the cross-linking reaction of PIP can be enhanced by the presence of BPO at times less than $12 \mathrm{~h}$. At long reaction times, $24 \mathrm{~h}$, this is diminished. In the presence of BPO the relative intensity is roughly constant for both PCP and PIP. The general changes in the DCP systems are opposite to those in the BPO system. The differences between PCP and PIP gradually decrease between 3 and $24 \mathrm{~h}$ reaction times; this is exactly consistent with the literature [2].

Table 23. Influence of reaction time $t$ on the maximal relative intensity $I_{\max }$ for cross-linked PCP and PIP

\begin{tabular}{|l|l|l|l|l|}
\hline System & PCP & & PIP & \\
\hline Reaction time $\boldsymbol{t} / \mathbf{h}$ & BPO & DCP & BPO & DCP \\
\hline 3 & 20.7 & 20.2 & 70.5 & 6.3 \\
\hline 6 & 27.9 & 14.9 & 61.8 & 11.7 \\
\hline 12 & 15.1 & 25.4 & 22.1 & 12.3 \\
\hline 24 & 13.2 & 29.5 & 13.9 & 25.6 \\
\hline
\end{tabular}

We now turn to the plasmon loss, $\Delta E_{\mathrm{L}}$. Looking at the onset temperatures derived from Table 6 , Table 7 , Table 8, Table 9 (PCP/BPO), 11-14 (PIP/BPO), 15-18 (PCP/DCP) and 19-22 (PIP/DCP) and corresponding Fig. 12, Fig. 13 , Fig. 14, Fig. 15, one may conclude that charring always occurs earlier for PCP than PIP, by about $60^{\circ} \mathrm{C}$ in case of $\mathrm{BPO}$, and more than $100^{\circ} \mathrm{C}$ in the case of DCP. This is clearly due to the presence of chlorine atoms and double bond in polymeric matrices although the differences between PCP and PIP seem to be unimportant in relative intensity along with the progressive extension of reaction time $t$.

\subsubsection{Comparison of thermal stability of PCP characterized by $T 60 \%$}

Chlorine loss must produce double bonds which may then undergo a cross-linking reaction. Another way to distinguish the thermal stability of PCP cross-linked with BPO or DCP involves the loss of chlorine. As an indication of cross-linking, it has been somewhat arbitrarily decided to use the temperature $T_{60 \%}$ at which $60 \%$ of the chlorine has been lost, i.e. the char contains $40 \%$ of the chlorine. This data is collected in Table 24 and one can see that the $T_{60 \%}$ is relatively constant for BPO up to $12 \mathrm{~h}$ reaction time. The $T_{60 \%}$ is higher for DCP, indicating that BPO is more effective than DCP is promoting cross-linking of PCP. 
Table 24. $T_{60 \%}\left({ }^{\circ} \mathrm{C}\right)$ values derived from $\mathrm{C} 12 \mathrm{p}$ spectra for PCP

\begin{tabular}{|l|l|l|}
\hline Reaction time/h & PCP cross-linked by BPO & PCP cross-linked by DCP \\
\hline 3 & 242 & 285 \\
\hline 6 & 240 & 280 \\
\hline 12 & 245 & 260 \\
\hline 24 & 260 & 260 \\
\hline
\end{tabular}

\section{Conclusion}

There are a number of issues concerning the measure of thermal degradation and charring of polymers upon heating that must be addressed and XPS provides a very useful technique to address these questions. One can conclude as follows:

1. Parameters derived from XPS, such as the relative intensity of carbon, the plasmon loss peak $\left(\Delta E_{\mathrm{L}}\right)$ in $\mathrm{C} 1 \mathrm{~s}$ spectra and the atomic concentration of chlorine in C12p spectra are the most important for the characterization of cross-linking and char formation.

2. Much lower relative intensity for original PIP than PCP was observed. The relative intensity does not exceed $10 \%$ for PIP below $380^{\circ} \mathrm{C}$ which is in agreement with the fact that plasmon loss $\left(\Delta E_{\mathrm{L}}\right)$ remains constant $(\sim 22.0 \mathrm{eV})$ up to $380^{\circ} \mathrm{C}$. In fact very little cross-linking and cross-link density appear until $380^{\circ} \mathrm{C}$.

3. There exists a great increase in the plasmon loss for both PCP and PIP, particularly for PCP. This indicates that cross-linking and charring reactions for PCP proceed at an extremely high rate within the narrow interval of $10^{\circ} \mathrm{C}$, possibly due to the coexistence of chlorine atoms attached to carbon and double bonds in the backbone.

4. The cross-linking reaction for PIP on heating can be extensively enhanced by BPO at least at $t<12 \mathrm{~h}$. This effect is diminished as the time increases to $24 \mathrm{~h}$. In the presence of DCP the relative intensity stays more or less constant for both PCP or PIP.

5. The relative intensity of PIP/BPO at $3 \mathrm{~h}$ on heating gives a surprisingly high value of ca $70 \%$. Unlike the original PIP, which does not undergo cross-linking upon heating, cross-linking of PCP developed in almost all the samples reacted with $\mathrm{BPO}$ at $70^{\circ} \mathrm{C}$ within the time period 3 to $24 \mathrm{~h}$.

6. An extremely high $I_{\max }$ (70.5\%) had been observed for PIP, in contrast to PCP (20.7\%), in the presence of BPO at. $t=3 \mathrm{~h}$, even though the original PCP does display higher intensity than PIP in the absence of initiators.

7. In the presence of DCP the relative intensity stays more or less constant whether PCP or PIP is used. Changes for the DCP system are opposite to those observed with BPO.

8. The differences between PCP and PIP gradually decrease when the reaction time increases from 3 to $24 \mathrm{~h}$. This must be indicative of a significant difference between the initiators.

9. On the basis of the plasmon loss, $\Delta E_{L}$, the onset temperatures indicate that charring always occurs earlier for PCP than PIP. This is clearly due to the presence of chlorine atoms and double bonds in the polymer.

\section{References}

[1] Balabanovich AI, Schnabel W, Levchik GF, Levchik SV, Wilkie CA. In: Le Bras M, Camino G, Bourbigot S, Delobel R, editors. Fire retardancy of polymers: the use of intumescence. London: Royal Society of Chemistry, 1998. p. 236.

[2] Schnabel W, Levchik GF, Wilkie CA, Jiang DD, Levchik SV. Polym Degrad Stab 1999;63:365. Jiang DD, Levchik GF, Levchik SV, Wilkie CA. Polym Degrad Stab 1999;65:387.

[3] D.D Jiang, G.F Levhcik, S.V Levchik, C Dick, J.J Liggat, C.E Snape, C.AWilkie. Polym. Degrad. Stab., 68 (2000), p. 75 
[4] Wang JQ, Tu HB. Proceedings of the 2nd Beijing International Symposium/Exhibition on Flame Retardants, Beijing, China, 1993. p. 272.

[5] J Wang, H Tu, Q Jiang. J. Fire Sci., 13 (1995), p. 261

[6] Wang JQ. In: Nelson GL, editors. Fire \& polymers II, materials \& tests for hazard prevention. Washington, DC: American Chemical Society, 1995. p. 518.

[7] Wang J. Proceedings of the 7th Annual BCC Conference on Flame Retardancy, Stamford, 1996.

[8] J Hao, J Wu, C Wilkie, J Wang. Polym. Degrad. Stab., 66 (1999), p. 81

[9] D.L Gardner, I.C McNeill. Eur. Polym. J., 7 (1971), p. 569

[10] M.A Golub, R.J Garginlo. Polym Letter, 10 (1972), p. 41

[11] J Wang. M Le Bras, G Camino, S Bourbigot, R Delobel (Eds.), Fire retardancy of polymers: the use of intumescence, Royal Society of Chemistry, London (1998), p. 159

[12] Li B. Doctoral Thesis, Beijing Institute of Technology, Beijing, China, 1997.

[13] B Li, J Wang. J. Fire Sci., 15 (5) (1997), p. 341

[14] B Li, J Wang. Chinese Sci Bull, 43 (13) (1998), p. 1090

[15] J Wang, B Li. Polym. Degrad. Stab., 63 (1999), p. 279 